\title{
Effect of statins on the inflammatory biomarkers of COPD
}

Keywords: cytokines, COPD, Kashmir, hematopoietic system, biomarkers

Abbreviations: BOLD, burden of lung disease; GM-CSF, granulocyte monocyte colony stimulating factor; CRP, primarily $\mathrm{C}$ - reactive protein; FEV1, expiratory volume in first second; IEC, institutional ethics committee; ADRs, adverse drug reactions

\section{Introduction}

The Burden of Lung Disease (BOLD) Study has documented more severe diseases than previously found with a substantial prevalence of (3-11\%) of COPD in never smokers. ${ }^{1}$ Worldwide prevalence of COPD ranges from $4-6 \%{ }^{2}$ In India documented prevalence is up to $4.1 \%$ with males $(5 \%)$ and females $(3.2 \%){ }^{3}$ Study from Kashmir pointed to a higher prevalence of $7.5 \%$ in smokers and $10.5 \%$ in people living in poorly ventilated houses. ${ }^{4}$ Although most of the available data on the disease are reported from the western world, it is being equally recognized from Asia and Africa. ${ }^{5}$ It continues to cause a heavy health and economic burden in US and around the world. ${ }^{6}$ Although COPD is characterized primarily by the presence of largely fixed airflow limitation but there is increasing evidence and acceptance that COPD can no longer be defined as a diseases restricted to lungs. ${ }^{7}$ The oxidant load derived from the lung (exogenous and endogenous) crosses the endothelium, where in combination with elevated circulating cytokines, it results in systemic inflammation in the vascular system. ${ }^{8,9}$ Smoke exposure further initiates the release of other inflammatory cytokines from variety of cells including interleukin 6 (IL6), tumor necrosis factor $(\mathrm{TNF} \alpha)$, transforming growth factor (TGF- $\beta 1$ ), and granulocyte monocyte colony stimulating factor (GM-CSF). ${ }^{10}$ Stimulation of hematopoietic system with the release of polymorph nuclear leucocytes, systemic oxidative stress, activation of coagulation factors and a direct effect on the endothelial function of the peripheral vessels have been attributed to smoking. ${ }^{11}$ Recent studies have shown a consistent association between biomarkers of systemic inflammation, primarily $\mathrm{C}$ - reactive protein (CRP) and severity of COPD.${ }^{12}$ The link between IL6, CRP and COPD is supported by the population based studies showing an inverse relationship between these biomarkers and forced expiratory volume in first second (FEV1). ${ }^{13,14}$ According to GOLD Guidelines, a diagnosis of COPD can be established by a fixed ratio of post bronchodilator FEV1 and FVC below 0.7 measured by spirometery. ${ }^{15}$ In summary there is growing evidence that COPD is associated with systemic inflammation that is exaggerated by, but not dependent on cigarette smoking. ${ }^{16}$ These observations are consistent with the hypothesis that lung function is not just a barometer to the lung response to airway aero pollutant exposure but also a matter of a more general systemic response. ${ }^{17}$ Over the past years, the understanding of COPD has evolved from it being a disease affecting the lungs to it being a complex, heterogeneous and generalized disorder in an aging population. ${ }^{7}$ The treatment of COPD is no longer focused exclusively on inhaled therapy but is taking on a multidimensional approach. ${ }^{7}$ Recently statins have emerged as a possible disease modifying agent in COPD. ${ }^{18}$ Evidence shows that statins possess pleotropic effects in addition to their conventional
Volume 8 Issue 4 - 2020

\author{
Shagufta Parveen, Nasreen Jan, Shaheen \\ Rasool \\ Department of Pharmacology, Kashmir University, India
}

Correspondence: Nasreen Jan, Department of Pharmacology, Kashmir University, Tel 9419017365, India,

Email nasrenchashoo@yahoo.co.in

Received: October 29, 2020 | Published: December 28, 2020

cholesterol lowering properties including anti-inflammatory, antioxidant, anti thrombogenic and vascular functions restoring actions. ${ }^{19}$ The rationale for their use in COPD partly derives from the fact that the pathogenesis of COPD involves inflammatory processes ${ }^{18}$ and persistent systemic inflammation seems to be present even in patients with stable COPD who do not currently smoke. ${ }^{9}$ This study aims at investigating the effect of statins on the biomarkers of inflammation present in COPD.

\section{Aims and objectives}

This study was conducted to evaluate the effect of statins on the systemic and lung specific biomarkers of inflammation related to COPD.

\section{Materials and methods}

After the approval from Institutional Ethics Committee (IEC) of Sheri-Kashmir Institute of Medical Sciences (SKIMS) Srinagar with IEC reference: Protocol 40/2012, the study was conducted at Department of Clinical Pharmacology as a study Centre in collaboration with the Department of General Medicine, Department of Immunology and Molecular Medicine. The study incorporated patients attending SKIMS Srinagar, Kashmir, which is a Tertiary Care Institute. Patients suffering from respiratory ailments visiting Pulmonary Clinic of Department of General Medicine were screened for the study cohort. The study was a hospital based, prospective, double blind, randomized, placebo controlled, parallel group clinical trial with the treatment allocation in three identical groups. A minimum sample size of 172 subjects was calculated for the study based on the expected 9\% prevalence of COPD in Kashmir with desired confidence level of 0.05 and margin of error 3\%. All patients attending the COPD clinic were screened by a physician, also the site specific co-investigator. Selected participants who after being explained the various aspects of the study summarily and after making them understand the purpose and rights, using their own language whenever necessary, consented to be the participants and signed the formal consent form along with witnesses and investigator. Diagnostic criteria for COPD as outlined by GOLD 201115 were followed. Eligible participants comprised of adults with: 
1. Age between 50-70 years irrespective of gender.

2. Clinical diagnosis of COPD as per GOLD criteria.

3. Population likely to have acute exacerbation should have one or more of the following conditions:

4. Be using supplemental $\mathrm{O}_{2}$,

5. Receiving a course of systemic corticosteroids and/or antibiotics for respiratory problem.

6. Visiting emergency department or being hospitalized for COPD exacerbations within past year.

At the initial visit, complete history, general physical examination and base line investigations along with Spirometery (lung function test) and laboratory investigations of systemic and lung specific biomarkers of inflammation (CRP, IL6, IL8) were performed before intervention and repeated six months after intervention. Analysis of the laboratory markers determined in the study was conducted in the Department of Immunology \& Molecular Medicine SKIMS under the supervision of site specific co-investigator. The Human ELISA kit was used for the in-vitro quantitative determination of interleukin- 6 (IL-6) and interleukin-8 (IL-8) in human plasma. High sensitivity C Reactive Protein (hsCRP) was measured by ELISA.

\section{Intervention}

In addition to conventional treatment of COPD, patients received either treatment A (Test drug Atrovastatin 40mg) or treatment B (Atrovastatin 10mg) or control treatment C (matched placebo) intervention according to pre designed random allocation. Patients were advised to take the single dose orally daily at bed time for a period of six months. The treatment was implemented and supervised jointly by the investigators from Department of General Medicine and Department of Clinical Pharmacology and regular periodic follow ups for drug compliance, any adverse drug effect, hospital admission or deterioration in existing clinical condition within the six months period. At the completion of six months, patients were called for monitoring of outcomes (clinical and laboratory outcomes) as well as any adverse drug reactions (ADRs). The trial drug and placebo in different doses i.e., Atorvastatin $10 \mathrm{mg}$ and $40 \mathrm{mg}$ was arranged by the co-investigator from Department of General Medicine as a bonfire contribution to the cause of research and development by the Ranbaxy laboratory under its social corporate responsibility programme. The lots of this investigational material were directly received by the interventionist who then was responsible for allocation concealment.

\section{Statistical analytical methods}

Categorical variables were analyzed by using the Chi square test and continuous variables were analyzed by using Student's t-test and one way ANOVA. Odds ratio and Confidence interval for COPD and for the effect of age, sex, ethnic group, Body Mass Index, smoking status, education and socioeconomic status were calculated. Multivariate statistics analysis was carried out where ever needed. Analysis was done using standard statistical software's like SPSS and Minitab.

\section{Results}

Patients ( $\mathrm{n}=172$ ) clinically diagnosed as COPD, fulfilling the GOLD criteria of COPD, between the age 40- 70 years of age, irrespective of gender and smoking status were randomized into treatment allocation groups A, B and C. Number of patients was matched as far as possible for age and gender in three treatment allocation groups. In our study the role of statins in COPD patients has been investigated with respect to the levels of inflammatory markers associated with the disease The levels of various biomarkers pre and post intervention were compared across the study groups (Table 1). ANOVA shows pre CRP concentration across the three study groups A $(5003.93,3551) \mathrm{B}$ $(5889.88,3882) \& C(5938.07,3870)$ are comparable $(\mathrm{p}>0.05)$. Post intervention hsCRP concentration across the three groups A, B and C were $(3752.043058,4449.22,4188,5220.61,3986)$. On comparing decrease in levels post intervention although not significant ( $p>0.05)$ is maximum in group A followed by group B and least in group C (Table 2). The respective mean IL6 levels in Groups A, B and C before intervention were observed as $303.44 \pm 58.8,250.86 \pm 62.1$ and 265.21 $\pm 55.6(p>0.05)$. After the intervention for six months changes observed in the levels across the three groups (A, B and C $57.17 \pm 93.0,78.44 \pm 17.9,141.34 \pm 14.9)$ revealed statistically significant difference among the three groups $(\mathrm{p}<0.05)$. Post Hoc test for multiple comparison done by least significant difference (LSD) test as shown in Table 3 revealed that the Pre intervention comparison of IL6 levels across the three groups revealed statistically no significant difference ( $>0.05)$, but there was a statistically significant difference in the post intervention means IL6 levels between group A and group C $(\mathrm{p}<0.05)$. Also there was a statistically significant differences in the post intervention mean IL6 levels between group B and group C $(\mathrm{p}<0.05)$, however mean IL6 levels of group A and group B did not differ significantly $(>0.05)$ post intervention (Table 4$)$. Post Hoc test for multiple comparison done by least significant difference (LSD) test as shown in Table 5 revealed that Pre intervention comparison of IL8 was significantly high in group A and $\mathrm{C}$ as compared to group $\mathrm{B}$ $(p<0.05, p<0.05)$, and there was a statistically significant difference in the post intervention means IL8 levels between group A and group $\mathrm{C}(\mathrm{p}<0.05)$ as well. On making comparison between group B and group $\mathrm{C}$, a statistically significant differences in the post intervention mean IL8 levels was observed between the two groups $(p<0.05)$, however the mean IL8 levels of group A and group B did not differ significantly $(\mathrm{p}>0.05)$ post intervention.

Table I Comparison of pre and post intervention C reactive protein levels across the study groups

\begin{tabular}{|c|c|c|c|c|c|c|c|}
\hline \multirow{3}{*}{ Group } & \multirow{3}{*}{ No. of patients } & \multirow{2}{*}{\multicolumn{2}{|c|}{ Mean+SD }} & \multicolumn{4}{|c|}{$95 \% \mathrm{Cl}$ for mean } \\
\hline & & & & \multicolumn{2}{|c|}{ Lower bound } & \multicolumn{2}{|c|}{ Upper bound } \\
\hline & & Pre CRP & Post CRP (ng/ml) & Pre CRP & Post RP & Pre CRP & Post CRP \\
\hline A & 54 & $5003.93 \pm 551.58$ & $3752.04 \pm 358.22$ & 3936.91 & 2833.25 & 6070.94 & 4670.83 \\
\hline B & 49 & $5889.88+882.18$ & $4449.22 \pm 188.60$ & 4576.34 & 3032.00 & 7203.43 & 5866.44 \\
\hline C & 60 & $5938.07 \pm 870.61$ & $5220.61 \pm 986.36$ & 9878.03 & 4110.80 & 6998.12 & 6330.42 \\
\hline Overall & 172 & $5608.96 \pm 740.48$ & $4514.93 \pm 782.19$ & 4967.39 & 3866.19 & 6250.54 & 5163.66 \\
\hline
\end{tabular}


Table 2 Comparison of pre and post intervention IL6 levels across the study groups

\begin{tabular}{|c|c|c|c|c|c|c|c|}
\hline \multirow{3}{*}{ Group } & \multirow{3}{*}{$\begin{array}{l}\text { No. of } \\
\text { patients }\end{array}$} & \multirow{2}{*}{\multicolumn{2}{|c|}{ Mean $\pm S D$}} & \multicolumn{4}{|c|}{$95 \% \mathrm{Cl}$ for mean } \\
\hline & & & & \multicolumn{2}{|c|}{ Lower bound } & \multicolumn{2}{|c|}{ Upper bound } \\
\hline & & Pre IL6 & $\begin{array}{l}\text { Post IL6 } \\
\mathrm{pg} / \mathrm{ml}\end{array}$ & Pre IL6 & Post IL6 & Pre IL6 & Post IL6 \\
\hline A & 54 & $303.44+58.58$ & $57.17 \pm 93.00$ & 105.58 & 29.23 & 501.30 & 85.12 \\
\hline$B$ & 49 & $250.86 \pm 62.19$ & $78.44 \pm \mid 7.91$ & 26.80 & 41.93 & 474.91 & 114.95 \\
\hline C & 69 & $265.21 \pm 55.68$ & $|4| .34 \pm \mid 4.95$ & 110.50 & 101.26 & $4 \mid 9.91$ & 181.42 \\
\hline Overall & 172 & $274.26 \pm 66.94$ & $95.84 \pm 14.04$ & 168.44 & 101.26 & 380.08 & 181.42 \\
\hline
\end{tabular}

Table 3 Post hoc test for comparison of IL6 levels pre and post intervention among three study groups

\begin{tabular}{|c|c|c|c|c|c|c|c|}
\hline \multirow[t]{2}{*}{$\begin{array}{l}\text { Dependent } \\
\text { variable }\end{array}$} & \multirow[t]{2}{*}{$\begin{array}{l}\text { (I) } \\
\text { Groups }\end{array}$} & \multirow{2}{*}{$\begin{array}{l}\text { (J) } \\
\text { Groups } \\
\text { Group B }\end{array}$} & \multirow{3}{*}{ 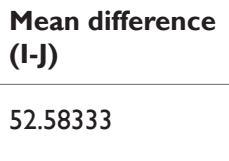 } & \multirow{3}{*}{$\begin{array}{l}\text { Std. error } \\
138.92470\end{array}$} & \multirow{3}{*}{$\begin{array}{l}\text { Sig. } \\
.706\end{array}$} & \multicolumn{2}{|c|}{$\begin{array}{l}95 \% \text { Confidence interval } \\
\text { lower upper bound }\end{array}$} \\
\hline & & & & & & -222.2626 & 327.4292 \\
\hline & Group A & & & & & & \\
\hline & & Group C & 38.23291 & | 26.49472 & .763 & -212.0218 & 288.4876 \\
\hline & & Group A & -52.58333 & 138.92470 & .706 & -327.4292 & 222.2626 \\
\hline \multirow[t]{9}{*}{ Pre IL6 } & Group B & & & & & & \\
\hline & & Group C & -14.35043 & I 34.70474 & .915 & -280.8477 & 252.1468 \\
\hline & & Group A & -38.23291 & 126.49472 & .763 & -288.4876 & 212.0218 \\
\hline & Group C & & & & & & \\
\hline & & Group B & 14.35043 & I 34.70474 & .915 & -252.1468 & 280.8477 \\
\hline & & Group B & -21.26667 & 26.63934 & .426 & -73.9694 & 31.4361 \\
\hline & Group A & & & & & & \\
\hline & & Group C & $-84.16838(*)$ & 24.25584 & .001 & -132.1557 & $-36 .|8| 1$ \\
\hline & & Group A & 21.26667 & 26.63934 & .426 & -31.4361 & 73.9694 \\
\hline \multirow[t]{5}{*}{ Post IL6 } & Group B & & & & & & \\
\hline & & Group C & $-62.9017 \mid(*)$ & $25.830 \mid 4$ & .016 & -114.0036 & -11.7999 \\
\hline & & Group A & 84.I6838(*) & 24.25584 & .001 & 36.1811 & 132.1557 \\
\hline & Group C & & & & & & \\
\hline & & Group B & $62.90171(*)$ & 25.83014 & .016 & II.7999 & II 4.0036 \\
\hline
\end{tabular}

*The mean difference is significant at the 0.05 level

Table 4 Comparison of pre and post intervention IL8 levels across the study groups

\begin{tabular}{|c|c|c|c|c|c|c|c|}
\hline \multirow{3}{*}{ Group } & \multirow{3}{*}{$\begin{array}{l}\text { No. of } \\
\text { patients }\end{array}$} & \multirow{2}{*}{\multicolumn{2}{|c|}{ Mean+SD }} & \multicolumn{4}{|c|}{$95 \% \mathrm{Cl}$ for mean } \\
\hline & & & & \multicolumn{2}{|c|}{ Lower bound } & \multicolumn{2}{|c|}{ Upper bound } \\
\hline & & Pre IL8 & $\begin{array}{l}\text { Post IL8 } \\
\text { pg/ml }\end{array}$ & Pre IL8 & Post IL8 & Pre IL8 & Post IL8 \\
\hline$A$ & 54 & $3081.20 \pm 222.52$ & $948.77 \pm 150.40$ & 2443.52 & 633.20 & 3718.87 & 1264.35 \\
\hline$B$ & 49 & $2076.66 \pm 182.09$ & $994.88 \pm 184.90$ & | 406.02 & 593.97 & 2747.31 & 1395.80 \\
\hline C & 69 & $3037.01 \pm 229.54$ & $2012.82 \pm 286.54$ & 2388.47 & $143 \mid .92$ & 3685.56 & 2593.72 \\
\hline Overall & 172 & $2792.02+298.14$ & $|377.27 \pm| 68.2 \mid$ & 2414.99 & 1096.28 & 3169.05 & 1658.26 \\
\hline
\end{tabular}

Mean concentration of IL8 before and after intervention observed in three study groups A, B and C are 308I.20 $\pm 222.5,2076.66 \pm$ I 82.0 and 3037.0 I \pm 229.5 and $948.77 \pm 150.4,994.88 \pm 184.9,2012.82 \pm 286.5$ respectively 
Table 5 Post hoc test for comparison of IL8 levels; pre and post intervention

\begin{tabular}{|c|c|c|c|c|c|c|c|}
\hline & \multirow{2}{*}{$\begin{array}{l}\text { (I) } \\
\text { Groups }\end{array}$} & \multirow{2}{*}{$\begin{array}{l}\text { (J) } \\
\text { Groups }\end{array}$} & \multirow{2}{*}{$\begin{array}{l}\text { Mean difference } \\
(\mathrm{I}-\mathrm{J})\end{array}$} & \multirow{2}{*}{ Std. error } & \multirow{2}{*}{ Sig. } & \multicolumn{2}{|c|}{ 95\% Confidence interval } \\
\hline & & & & & & Lower bound & Upper bound \\
\hline \multirow{6}{*}{ Pre IL8 } & \multirow{2}{*}{ Group A } & Group B & $1004.53333(*)$ & 485.36037 & .040 & 44.3059 & 1964.7608 \\
\hline & & Group C & 44.18077 & 441.93383 & .921 & -830.1325 & 918.4940 \\
\hline & \multirow{2}{*}{ Group B } & Group A & $-1004.53333(*)$ & 485.36037 & .040 & -1964.7608 & -44.3059 \\
\hline & & Group C & $-960.35256(*)$ & 470.61712 & .043 & $-|89| .4123$ & -29.2929 \\
\hline & \multirow{2}{*}{ Group C } & Group A & -44.18077 & 441.93383 & .921 & -918.4940 & 830.1325 \\
\hline & & Group B & $960.35256(*)$ & 470.61712 & .043 & 29.2929 & 1891.4123 \\
\hline \multirow{6}{*}{ Post IL8 } & \multirow{2}{*}{ Group A } & Group B & -46.111111 & 350.67245 & .896 & -739.8746 & 647.6524 \\
\hline & & Group C & $-|064.049| 5(*)$ & 319.29682 & .001 & -1695.7397 & -432.3586 \\
\hline & \multirow{2}{*}{ Group B } & Group A & 46.111111 & 350.67245 & .896 & -647.6524 & 739.8746 \\
\hline & & Group C & $-1017.93803(*)$ & 340.02047 & .003 & -1690.6279 & -345.2482 \\
\hline & \multirow{2}{*}{ Group C } & Group A & $1064.04915(*)$ & 319.29682 & .001 & 432.3586 & 1695.7397 \\
\hline & & Group B & $1017.93803(*)$ & 340.02047 & .003 & 345.2482 & 1690.6279 \\
\hline
\end{tabular}

*The mean difference is significant at the 0.05 level

\section{Discussion}

Inflammation is considered central to the pathogenesis ${ }^{20}$ of COPD and statins have been shown to possess a diverse range of pleotropic effects including anti-inflammatory actions and recent evidence suggests statins reduce pulmonary inflammation. ${ }^{21-23}$ It is expected that they may also suppress the inflammation associated with cigarette smoke and ameliorate the associated structural and functional abnormalities in the lungs of COPD patients. ${ }^{22,24}$ Considering this fact the present study besides focusing on the clinical outcomes, laboratory outcomes of inflammation like hsCRP, IL6 and IL8, which have been shown to be affected by statins have been assessed as the primary outcomes of this study. Patients in the present study have shown significantly increased levels of these inflammatory markers ( hsCRP, IL6 and IL8) associated with their disease at the onset of study which after six months intervention with statins were markedly brought down in the test groups as compared to controlled group. Levels of hsCRP in patients who received $40 \mathrm{mg}$ daily of the test drug for a period of six months have shown decrease in the levels although statistically insignificant $(\mathrm{p}>0.05)$. However, patients who received 10 $\mathrm{mg}$ of statins although appear to experience a beneficial effect but the difference in the size of effect is less compared to group A (Table1). It will be inferred from these observations that the beneficial effects of statins on the concentration of hsCRP consistently are more seen at higher doses than at lower doses.

Raised levels of representative pro inflammatory cytokines, IL6, CRP have been shown to be associated with low FEV125.25 During the last decade, several studies investigating the systemic manifestations of the COPD have reported enhanced levels of circulating inflammatory mediators such as acute phase reactants and cytokines. Scholls and colleagues demonstrated increased levels of CRP in patients with stable COPD ${ }^{26}$ Certain meta-analyses have shown that patients of COPD have higher serum concentration of CRP than healthy controls and that the serum concentration might be an indicator of disease severity. ${ }^{26,27}$ Taking hsCRP as primary outcome in the study as a marker of inflammation in the patients of COPD is because of its low cost of measurement and convenience in the procedure besides it may be the marker of disease progression. Such evidence might help physicians to stratify patients with COPD in terms of their risk of disease progression so that early intervention strategies are implemented to modify the risk. Only few studies have evaluated the effect of statins on the inflammatory markers on bases of severity and analyzed the CRP levels only. One or two studies have compared simvastatin $40 \mathrm{mg}$ to placebo in patients with COPD and evaluated CRP levels as the primary outcome. ${ }^{28-30}$

To validate the beneficial effects of statins on the inflammatory markers associated with the COPD and thereby modify the clinical course, the present study has distinctly compared outcome of both acute phase reactants like CRP as well as cytokines IL6 and IL8 with the six months statin therapy. Additionally the effect was compared with two different dosages of the test drug. So far it was not possible to locate any study in which all the features were combined together. Besides assessing the clinical end points, present study has determined the effect of statins on the various inflammatory mediators like IL6, IL8 besides CRP which are now considered key determinants in the pathogenesis of COPD. Pre intervention concentration of IL6 of the patients although very high in comparison to normal levels were comparable across the three study groups (Table 2, $\mathrm{p}>0.05$ ). However statin therapy for a period of six months have significantly lowered the levels in the test groups ( $A$ vs $B ; p>0.05$ ) when compared with controls or group C (A vs $C ; p<0.05$ ), (B vs $C$; $p<0.05$, Table $3)$.Within the two test groups $A$ and $B$, different dosages of the drug ( $40 \mathrm{mg}$ and $10 \mathrm{mg}$ ) has not much changed the effect between the two groups. Somewhat similar observations were revealed when IL8 concentrations were compared pre and post statin therapy across the three respective groups. Mean concentration of IL8 in group A and C was significantly higher than group B before intervention. However, with six months statin intervention, change in the levels was highly significant in group A as compared to group $C(p<0.05)$. Similar results were observed in group B where again significant change in levels was seen when compared with control group $(\mathrm{p}<0.05$; Table 5$)$. Overall improvement in levels of the inflammatory markers involved in COPD has been observed by the intervention. From the above 
observations we conclude that statin therapy for a prolonged period seems to be beneficial overall for improving the clinical as well as laboratory parameters in COPD. It was also observed that throughout the course of study, it generally did not evoke any adverse effect in participants. Symptoms of acid peptic diseases at the initiation of treatment reported by one patient was reported to PvPI center of SKIMS.

\section{Conclusion}

This study was carried out with the main focus to analyze the effect of statins on levels of inflammatory markers in COPD in Kashmiri population ethnically different from the rest of the country. The study may hopefully contribute and substantiate importance and rationale of adding statins to the existing treatment options of COPD. Froude that COPD is associated with increase in certain inflammatory markers and a significant reduction in their levels by the six month therapy with statins is associated with the improvement in the clinical course of the disease. Like other few studies, the results of present study have conferred that statins have significant additional benefits in COPD where elevated levels of various inflammatory mediators is a feature and statins target the pulmonary inflammation only. Present study reveals that statins have a significant beneficial effect not only on CRP but also on other important markers of inflammation. Therefore, statins may represent a new and much needed additional treatment strategy in the patients of COPD especially in our setup where the climatic as well as socio-economic conditions have proven to add to the number of patients and additionally worsen the condition of those already suffering from the disease.

\section{Conflicts of interest}

The authors declare that they have no conflict of interest.

\section{Acknowledgments}

None.

\section{References}

1. Buist AS, McBurnie MA, Vollmer WM, et al. International variations in the prevalence of COPD (THE BOLD STUDY): a population based prevalence study. Lancet. 2007;370:741-750.

2. Nazir SA, Erbland ML. Chronic obstructive pulmonary disease: an update on diagnosis and management issues in older adults. Drugs Aging. 2009;26(10):813-831.

3. Jindal SK, Aggarwal AN, Chaudhry K, et al. Asthma epidemiology study group. A multicentric study on epidemiology of COPD and its relationship with tobacco smoking and environmental tobacco smoke exposure. IndianJ Chest Dis Allied Sci. 2006;48:23-27.

4. Akhtar MA, Latif PA. Prevalence of chronic bronchitis in urban population of Kashmir. J Indian Med Assoc. 1999;97:365-366.

5. Surinder K Jindal. Emergence of Chronic Obstructive Pulmonary Diseases as an epidemic in India. Indian J Med Res. 2006;124:619-630.

6. David MMannino. Epidemiology, Prevalence, Morbidity and Mortality, and Disease Heterogeneity. Chest. 2002;121:121S-126S.

7. Yvonne Nussbaumer-ochsner, Klaus F Rabe, Wouters EF, et al. Systemic Manifestations of COPD. CHEST. 2011;139(1):165-173.

8. Roth M. Pathogenesis of COPD. Part III. Inflammation in COPD. IntJ TubercLung Dis. 2008;12:375-380.

9. Gan WQ, Man SFP, Senthilselvan A, et al. Association between chronic obstructive pulmonary disease and systemic inflammation: a systematic review and a meta-analysis. Thorax. 2004;59:574-580.
10. Stockley RA. Neutrophils and the pathogenesis of COPD. Chest. 2002;121:151S-155S.

11. Yanbaeva DG, Dentener MA, Creutzberg EC, et al. Systemic effects of smoking. Chest. 2007;131(5):1557-1566.

12. Sin DD, Man PSF. Why are patients with chronic obstructive pulmonary disease at increased risk of cardiovascular disease? The potential role of systemic inflammation in chronic obstructive pulmonary disease. Circulation. 2003;107:1514-1519.

13. Yende S, Waterer GW, Tolley EA, et al. Inflammatory markers are associated with ventilatory limitation and muscle dysfunction in obstructive lung disease in well functioning elderly subjects. Thorax.2006;61:10-16.

14. Sin DD. Man SFP Interluekin 6. Chest. 2008;133:4-6.

15. Gold Global Strategy For the Diagnosis, Management, and Prevention of COPD. 2011.

16. Brass DM, Hollingsworth JW, Cinque M, et al. Chronic LPS inhalation causes emphysema-like changes in mouse lung that is associated with apoptosis. Am J Respir Cell Mol Biol. 2008;39:4-90.

17. Young RP, Hopkins RJ, Eaton TE. Forced expiratory volume in one second: not just a lung function test but a marker of premature death from all causes. Eur Resp J. 2007;30:616-622.

18. Barnes PJ, Shapiro SD, Pauwels RA. Chronic obstructive pulmonary disease: molecular and cellular mechanisms. Eur Respir J. 2003;22:672688.

19. Palinski W. New evidence for beneficial effects of statins unrelated to lipid lowering. Arterioscler Thromb Vasc Biol. 2001;21:3-5.

20. Pauwels RA, Buist AS, Calverley PM, et al. Global strategy for the diagnosis, management, and prevention of chronic obstructive pulmonary disease. NHLBI/WHO Global Initiative for Chronic Obstructive Lung Disease (GOLD) workshop summary. Am J Respir Crit Care Med. 2001;163:256-1276.

21. Altose MD. Aproaches to slowing the progression of COPD. Curr Opin Pulm Med. 2003;9125-9130.

22. Hothersall E, McSharry C, Thomson NC. Potential therapeutic role for statins in respiratory disease. Thorax. 2006;61(8):729-734.

23. Feldman C. The role of statins in respiratory diseases. Clin Pulm Med. 2009;16(2):95-100.

24. Hopkins R, Eaton T. Pharmacological actions of statins: Potential utility in COPD. Euro Resp Rev. 2009;18:114222-114232.

25. Mannino DM, Ford ES, Redd SC. Obstructive and restrictive lung disease and markers of inflammation: data from the Third National Health and Nutrition Examination. Am J Med. 2003;114:758-762.

26. Schols AM, Buurman WA, Staal van den Brekel AJ, et al. Evidence for a relation between metabolic derangements and increased levels of inflammatory mediators in a subgroup of patients with chronic obstructive pulmonary disease. Thorax. 1996;51:819-824.

27. Biljak VR, Pancirov D, Cepelak I, et al. Platelet count, mean platelet volume and smoking status in stable chronic obstructive pulmonary disease. Platelets. 2011;22:466-470.

28. Lee TM, Lin MS, Chang NC. Usefulness of C-reactive protein and interleukin- 6 as predictors of outcomes in patients with chronic obstructive pulmonary disease receiving pravastatin. Am J Cardiol. 2008;101:530535.

29. Effect of statin therapy on C-reactive protein levels in patients with chronic obstructive lung disease (COPD). 2009.

30. Lovastatin as a potential modulator of apoptosis in chronic obstructive pulmonary disease (COPD). 2009. 